\title{
O Conceito de Célula em Livros Didáticos de Biologia: ciência aproblemática e a-histórica
}

\author{
The Concept of Cell in Biology Textbooks: \\ aproblematic and ahistorical science
}

Regiane Machado de Sousa Pinheiro'

Adda Daniela Lima Figueiredo Echalar ${ }^{1}$

José Rildo de Oliveira Queiroz ${ }^{1}$

'Universidade Federal de Goiás (UFG), Programa de Pós-Graduação em Educação em Ciências e Matemática, Goiânia, GO, Brasil. Autora Correspondente: regianemachado0311@gmail.com

Resumo: Este artigo buscou compreender como é apresentado o conceito de célula nos livros didáticos de Biologia aprovados pelo Programa Nacional do Livro Didático (PNLD) 2015, por meio da análise dos aspectos conceituais e sócio-históricos desses livros, estabelecendo relações entre as visões de Biologia e de mundo presentes neles. Para tanto, utilizamos como base teórico-metodológica o materialismo histórico-dialético, bem como os Estatutos Estruturantes da Biologia. Os resultados apontam que a maioria das obras não faz referência à história da formação do conceito de célula, caracterizando uma visão de Ciência aproblemática, a-histórica, dogmática e fechada. Concluímos que a forma como o conteúdo de célula está disposto nos livros didáticos analisados não viabiliza a compreensão do pensamento biológico como parte integrante de um processo sócio-histórico.

Palavras-chave: Ensino de biologia; Pensamento biológico; Teoria celular; Livro didático.

Abstract: This article sought to explain how the concept of cell is presented in the Biology textbooks approved by the National Textbook Program (PNLD) 2015, through the analysis of the conceptual and socio-historical aspects of these books, establishing relationships between the views of Biology and of world present in them. To do that, we used historical-dialectical materialism as a theoretical-methodological basis, as well as the Structuring Statutes of Biology. The results show that most of the books do not refer to the history of the formation of the concept of cell, which characterizes a view of Science that is aproblematic, ahistorical, dogmatic, and closed. We conclude that the way the content on the cell is organized in the analyzed textbooks does not foster the understanding of biological thinking as an integral part of a socio-historical process.

Keywords: Biology teaching; Biological thinking; Cell theory; Textbooks.

Recebido em: 28/03/2020

Aprovado em: 19/10/2020 


\section{Introdução}

O Livro Didático (LD) é peça fundamental no processo de escolarização brasileira, sendo parte da cultura e das lembranças de muitas gerações. É instrumento pedagógico importante ao ensino e, por estar presente na maior parte das escolas, de certo modo é um dos suportes no processo de formação da sociedade (VASCONCELOS; SOUTO, 2003).

A importância do LD na Educação brasileira pode ser entendida, em termos históricos, por meio de sua relação com as práticas escolares, sendo certificada pela discussão em torno de sua função na democratização de saberes socialmente legitimados (MARTINS, 2012). Esta importância pode também ser identificada quando analisamos os interesses econômicos que envolvem sua produção e comercialização, os investimentos do governo nos programas de avaliação e distribuição e o debate travado sobre seu papel como possível estruturador da atividade docente. Outros aspectos podem ser levantados com relação a este recurso, sejam eles em sua ação didática, associada à produção cultural e ideológica da sociedade; pedagógica de caráter instrumental, por ser substrato de materialização de um currículo, bem como sua função meramente documental (CHOPPIN, 2004).

Além disso, observa-se que, muitas vezes, no processo de mediação didática docente, o LD assume centralidade no processo, impondo-se no contexto educativo. Essa influência é refletida desde a organização do planejamento do professor, bem como no desenvolvimento de sua prática pedagógica, na sala de aula. Desta forma, os livros didáticos "[...] representam em muitos casos o único material de apoio didático disponível para alunos e professores" (VASCONCELOS; SOUTO, 2003, p. 93). Isso é consequência da realidade do contexto educacional brasileiro devido às poucas condições materiais que as escolas públicas possuem, além de uma excessiva jornada de trabalho do professor, que dificulta ou impossibilita a busca por outros recursos didáticos. Todavia, esse recurso não pode atuar como responsável central de conteúdo e de mediação didática do processo de ensino e aprendizagem, inibindo o potencial criativo e pedagógico do professor, o agente desta ação.

Um livro para ser considerado didático precisa atender alguns requisitos, tais como, ser usado de maneira sistemática e conter conteúdo consolidado de uma disciplina escolar, de aprendizado coletivo e orientado por um professor (LAJOLO, 1996).

As pesquisas que analisam o LD como recurso didático no processo de ensino e aprendizagem de Biologia podem ser classificadas em quatro grupos: análise como conceitos/conteúdos são abordados nos livros didáticos; estrutura dos livros didáticos; a produção de material didático e o uso do LD no contexto da prática de ensino de professores de Ciências (FREITAS, 2016).

Dentre as diversas temáticas que são analisadas nos LD de Biologia, observase um destaque para conteúdos relacionados ao estudo da célula (BARBOSA, 2014; CAURIO, 2011). Isso se deve ao fato de a Teoria Celular ser um dos elementos centrais da Biologia. Sua promulgação determinou o substrato material do mundo orgânico, demonstrando que as células dos tecidos animais se originavam de forma semelhante à dos vegetais, e que qualquer tecido era composto por células. A teoria implantou um novo paradigma na Biologia que permitiu realizar uma atividade científica que almejasse 
a resolução teórica, a explicação e a justificação dos fenômenos que se tornaram seu objeto (NASCIMENTO JÚNIOR, 2010).

Apesar de existirem na literatura diversos trabalhos que têm o LD como objeto de estudo, consideramos que analisar esse material numa relação de não centralidade no objeto técnico, mas no desvelar do movimento lógico e de historicidade de um conceito, nos permite discutir e contribuir para a compreensão da pesquisa em Educação em Ciências e do LD no trabalho pedagógico, à luz da compreensão histórico-filosófica do conceito de célula. Isso porque o estudo da célula é um conceito-chave para a compreensão e organização biológica, sendo necessário que os estudantes a compreendam como uma estrutura fundamental e funcional da constituição dos organismos vivos (RODRÍGUEZ PALMERO; MOREIRA, 1999).

Neste artigo temos como objetivo responder ao seguinte questionamento: de que forma o conceito de célula é apresentado nos livros didáticos de Biologia? Almejamos compreender como é apresentado o conceito de célula nos livros didáticos de Biologia aprovados pelo Programa Nacional do Livro Didático (PNLD) 2015, por meio de uma análise dos aspectos conceituais e socio-históricos desses livros, buscando estabelecer relações entre as visões de Biologia e de mundo presentes neles.

\section{Percurso da Pesquisa}

Entendemos que o conteúdo apresentado no livro didático representa o conhecimento singular e aparente, o ponto de partida. O universal refere-se ao conhecimento da Biologia, mediado pelo trabalho docente e particularizado pela produção humana expressa no conteúdo célula. Assim, pautados na lógica dialética, buscamos a construção do conhecimento sistematizado sobre o fenômeno estudado.

A Biologia pode ser fundamentada, à luz da dialética, na interseção de quatro Estatutos Estruturantes, a saber: (1) ontológico: indica a visão de mundo, de natureza e de homem que se tem; (2) epistemológico: indica sob quais leis, modelos e teorias se pode explicar um fenômeno; (3) histórico-social: indica como a Biologia se constrói no contexto histórico e social; e, (4) conceitual: rede conceitual que permitem estabelecer as bases do conhecimento desta ciência por meio de temas e teorias que fundamental a Biologia (NASCIMENTO JÚNIOR, 2010; NASCIMENTO JÚNIOR; SOUZA; CARNEIRO, 2011; PINHEIRO, 2018).

A construção da matriz de coleta de dados foi fundamentada nos Estatutos Estruturantes da Biologia (NASCIMENTO JÚNIOR, 2010) e em seus estudos com currículo (NASCIMENTO JÚNIOR; SOUZA; CARNEIRO, 2011) a fim de subsidiar um olhar histórico e filosófico sobre o conceito de célula presente nos LD analisados (Quadro 1). 
Quadro 1 - Matriz de coleta de dados do conceito de célula em livros didáticos de Biologia aprovados no PNLD 2015

\begin{tabular}{|c|c|c|c|c|}
\hline \multicolumn{5}{|l|}{ Livro / Título do capítulo: } \\
\hline \multicolumn{5}{|l|}{ Autores: } \\
\hline \multicolumn{5}{|l|}{ Coleção: } \\
\hline \multirow[t]{2}{*}{ Aspectos Pedagógicos } & \multirow{2}{*}{$\begin{array}{c}\text { Síntese } \\
\text { Qualitativa } \\
\text { dos Dados }\end{array}$} & \multicolumn{3}{|c|}{ Escala Likert* } \\
\hline & & + & $+1-$ & - \\
\hline \multicolumn{5}{|l|}{ Conteúdo } \\
\hline \multicolumn{5}{|l|}{ Estatuto Ontológico } \\
\hline \multicolumn{5}{|l|}{ Elucida o movimento histórico de construção do conceito de célula? } \\
\hline \multicolumn{5}{|l|}{ Esclarece a construção histórica do conceito de organismo? } \\
\hline \multicolumn{5}{|l|}{ Permite perceber o movimento de construção do conceito de natureza? } \\
\hline \multicolumn{5}{|l|}{ Estatuto Epistemológico } \\
\hline \multicolumn{5}{|l|}{$\begin{array}{l}\text { Favorece o processo de construção da Teoria Celular, sinalizando modelos } \\
\text { consonantes com vertentes epistemológicas contemporâneas? }\end{array}$} \\
\hline \multicolumn{5}{|l|}{ Apresenta o método científico na Teoria Celular? } \\
\hline \multicolumn{5}{|l|}{ Apresenta o conceito de célula? } \\
\hline \multicolumn{5}{|l|}{ Estatuto Histórico-Social } \\
\hline \multicolumn{5}{|l|}{$\begin{array}{l}\text { Favorece o entendimento da construção do pensamento biológico a partir da } \\
\text { ideia de não linearidade da história da Teoria Celular? }\end{array}$} \\
\hline \multicolumn{5}{|l|}{$\begin{array}{l}\text { Relaciona o conhecimento biológico da Teoria Celular, desenvolvido } \\
\text { historicamente, com as transformações tecnológicas? }\end{array}$} \\
\hline \multicolumn{5}{|l|}{$\begin{array}{l}\text { Favorece o entendimento da construção do pensamento biológico a partir das } \\
\text { interpretações dependentes do contexto social em que foram produzidas? }\end{array}$} \\
\hline \multicolumn{5}{|l|}{$\begin{array}{l}\text { Favorece a construção do pensamento biológico a partir da origem política } \\
\text { das sociedades científicas? }\end{array}$} \\
\hline \multicolumn{5}{|l|}{$\begin{array}{l}\text { Favorece a construção do pensamento biológico a partir dos elementos } \\
\text { ideológicos do conhecimento biológico? }\end{array}$} \\
\hline \multicolumn{5}{|l|}{ Estatuto Conceitual } \\
\hline \multicolumn{5}{|l|}{$\begin{array}{l}\text { Articula os temas estruturadores da Biologia na construção do conhecimento } \\
\text { sobre a teoria celular? }\end{array}$} \\
\hline \multicolumn{5}{|l|}{$\begin{array}{l}\text { Utiliza, de modo claro e conciso, os conceitos e informações em exercícios, } \\
\text { atividades, ilustrações ou imagens? }\end{array}$} \\
\hline \multicolumn{5}{|l|}{$\begin{array}{l}\text { Apresenta conceitos, informações e procedimentos de modo correto, } \\
\text { contextualizado e atualizado? }\end{array}$} \\
\hline Aponta caminhos para problematização e reflexão sobre o cotidiano? & & & & \\
\hline
\end{tabular}

* $(+)$ = contempla; $(+/-)=$ contempla parcialmente e $(-)=$ não contempla Fonte: adaptado de Pinheiro (2018, p. 37).

No que diz respeito à nossa pesquisa, nosso campo empírico, denominado corpus da pesquisa, se constituiu das nove coleções de Biologia aprovadas pelo PNLD 2015 e, vale ressaltar, que esse trabalho é fruto de uma pesquisa concluída de mestrado em programa de pós-graduação brasileiro da área de Educação em Ciências e Matemática.

Cada questão da matriz foi sendo preenchida pelos pesquisadores após as leituras na íntegra dos capítulos e das informações contidas em cada Manual do Professor dessas coleções. Fundamentados na visão de Ciência, homem, sociedade e conhecimento do materialismo histórico-dialético (MHD), foram extraídos excertos e sínteses de cada item da matriz, compreendendo a coluna síntese qualitativa dos dados e, posteriormente, por meio das recorrências, fechou-se um resultado objetivo para cada livro na coluna da 
escala Likert, que é um tipo de escala que demonstra a concordância ou discordância dos aspectos analisados, medindo o grau de cada item perguntado - representa a soma das respostas dadas a cada item Likert -, medindo-se o grau de concordância ou discordância da afirmação (CRESWELL, 2007).

Para sintetizar o resultado da análise qualitativa utilizamos a escala Likert, para fins de síntese, a partir de três parâmetros: contempla (+) quando o conteúdo do LD aborda satisfatoriamente a discussão quanto ao item analisado; contempla parcialmente (+/-), quando o conteúdo do LD é apresentado de forma superficial ou parcial ao que se apresenta no item e não contempla (-), quando não aparece discussão quanto ao item em destaque.

Assim, a presente pesquisa, buscou analisar os LD sob uma concepção histórica do processo de construção da Biologia, numa perspectiva crítica, objetivando compreender as visões de Ciência e de mundo por meio do conceito de célula presente nos livros didáticos.

\section{Os Livros de Biologia do PNLD 2015: o nosso imediato}

Foram selecionados e analisados os nove livros da $1^{\text {a }}$ série do Ensino Médio das nove coleções de Biologia aprovadas pelo Programa Nacional do Livro Didático (PNLD) 2015, visto que o conceito de célula é desenvolvido no primeiro volume dessas obras (Quadro 2).

Quadro 2 - Obras de Biologia do PNLD 2015, com as referências dos capítulos analisadas

\begin{tabular}{|c|l|}
\hline $\begin{array}{c}\text { Código de } \\
\text { Identificação }\end{array}$ & \multicolumn{1}{|c|}{ Referência } \\
\hline LD 1 & $\begin{array}{l}\text { LOPES, S.; ROSSO, S. Citologia e envoltórios celulares. In: LOPES, S.; ROSSO, S. Bio. 2. ed. } \\
\text { São Paulo: Saraiva, 2013. v. 1, p. 206-208. }\end{array}$ \\
\hline LD 2 & $\begin{array}{l}\text { AMABIS, J. M.; MARTHO, G. R. A descoberta das células. In: AMABIS, J. M.; MARTHO, G. R. } \\
\text { Biologia em contexto. São Paulo: Moderna, 2013. v. 1. p. 172-177. }\end{array}$ \\
\hline LD 3 & $\begin{array}{l}\text { LINHARES, S.; GEWANDSZNAJDER, F. Uma visão geral da célula. In: LINHARES, S.; } \\
\text { GEWANDSZNAJDER, F. Biologia hoje. 2. ed. São Paulo: Ática, 2013. v. 1, p. 74-76. }\end{array}$ \\
\hline LD 4 & $\begin{array}{l}\text { OSORIO, T. C. et al. Introdução à Citologia. In: OSORIO, T. C. (org.). Ser protagonista: biologia. } \\
\text { 2. ed. São Paulo: Edições SM, 2013. v. 1, p. 64-68. }\end{array}$ \\
\hline LD 5 & $\begin{array}{l}\text { BRÖCKELMANN, R. H. et al. A descoberta da célula. In: BRÖCKELMANN, R. H. (org.). Conexões } \\
\text { com a biologia. São Paulo: Moderna, 2013. v. 1, p. 108-112. }\end{array}$ \\
\hline LD 6 & $\begin{array}{l}\text { MENDONÇA, V. L. Introdução à citologia e membranas celulares. In: MENDONÇA, V. L. } \\
\text { Biologia. 2. ed. São Paulo: Editora AJS, 2013. v. 1, p. 162-166. }\end{array}$ \\
\hline LD 7 & $\begin{array}{l}\text { SILVA JÚNIOR, C.; SASSON, S.; CALDINI JÚNIOR, N. A célula, unidade fundamental dos } \\
\text { seres vivos. In: SILVA JÚNIOR, C.; SASSON, S.; CALDINI JÚNIOR, N. Biologia. 11. ed. São } \\
\text { Paulo: Saraiva, 2013. v. 1, p. 201-205. }\end{array}$ \\
\hline LD 8 & $\begin{array}{l}\text { FAVARETTO, J. A. A célula: um sistema eficiente. In: FAVARETTO, J. A. Biologia: unidade e } \\
\text { diversidade. São Paulo: Saraiva, 2013. v. 1, p. 39-40. }\end{array}$ \\
\hline LD 9 & $\begin{array}{l}\text { BIZZO, N. A organização básica da vida. In: BIZZO, N. Novas bases da biologia. 2. ed. São } \\
\text { Paulo: Ática, 2013. v. 1, p. 24-27. }\end{array}$ \\
\hline
\end{tabular}

Fonte: Pinheiro $(2018$, p. 34).

Os livros selecionados foram caracterizados como fontes primárias e dados originais da nossa pesquisa por meio dos quais buscamos traçar a relação direta entre eles e a forma de pensar biológica e pedagogicamente o conceito célula. 
Todos os livros analisados destacam o início da Citologia por meio da apresentação das observações feitas pelo cientista inglês Robert Hooke (1635-1703), em seguida, fazem referência ao apogeu da Teoria Celular que se deu com as descobertas de Matthias Schleiden (1804-1881) e Theodor Schwann (1810-1882). Esses livros não destacam que esse período de construção científica se deu ao longo de quase 200 anos de pesquisas, conforme pode ser verificado nos trechos ${ }^{1}$ a seguir:

\begin{abstract}
Embora Hooke já houvesse observado a célula em 1665, somente em 1838 foi comprovada por Schleiden a existência da célula em plantas e em 1839 foi comprovada por Schwann a existência da célula em animais. [...] Esses dois cientistas, Schleiden e Schwann, estabeleceram o que ficou conhecido como doutrina celular:'todo ser vivo é formado por células'. (LD6, p. 166, grifo do autor).

Hooke afirmou que a cortiça era constituída por pequenos poros ou células, comparáveis aos pequenos compartimentos que compõem os favos de colmeias das abelhas. Foi a primeira vez que alguém utilizou o termo célula para referir-se à unidade básica dos tecidos vivos. [...] Mas foi apenas em meados do século XIX, graças aos trabalhos de cientistas como os alemães T. Schwann (1810), M, Schleiden (1839), que se generalizou o que hoje é conhecido como Teoria Celular. (LD7, p. 201-202, grifo do autor).
\end{abstract}

Nesses quase duzentos anos de história que poderiam ter sido explorados pelos livros didáticos analisados, diversos pesquisadores se interessaram pelo estudo da célula, como Marcello Malpighi (1628-1694), Antonie van Leeuwenhoek (1632-1723), Nehemiah Grew (1641-1712), Gottfried Treviranus (1776-1837), René Henri Dutrochet (1776-1847) e Lorenz Oken (1779-1851). Estes estudiosos também deixaram muitas contribuições para o estabelecimento da Citologia como área de estudo da Biologia, que poderiam ser utilizados pelos autores dos livros didáticos como uma fonte da historicidade do conceito de célula, que pode contribuir no processo de mediação didática docente ao planejar o processo de ensino e aprendizagem.

Outro aspecto observado com regularidade nesses livros é uma presença forte da visão antropocêntrica na qual ainda há uma dicotomia entre natural e cultural, sendo a natureza colocada a serviço do homem. Tal dissociação fundamenta-se na ética antropocêntrica humanista e no pensamento cartesiano, o qual situa o homem fora do mundo natural. Portanto, não é só a curiosidade e a necessidade de compreender a natureza que fazem os cientistas
estudarem a célula. Este estudo - a Citologia - ajuda o cientista a compreender melhor a origem
das doenças e facilita também a pesquisa de novos medicamentos e tecnologias. (LD3, p. 72).
[...] compreendendo melhor o que é célula e como ela funciona, você poderá também compreender
melhor "o que é a vida", o fenômeno que é o objeto de estudo da Biologia. E para a sua vida,
esses conhecimentos também poderão ter um papel importante. Cuidar da saúde é muitas vezes
sinônimo de cuidar de suas próprias células! (LD6, p. 163).

O objeto de estudo da Biologia é a manifestação da vida na Natureza e para estudar sua história é fundamental entender a relação entre a história natural e a história social da humanidade. Sendo assim, o homem se relaciona com a natureza reagindo sobre ela e transformando-a, para garantir sua própria existência. Nesse movimento,

${ }^{1}$ Os excertos extraídos dos livros didáticos (LD) analisados serão apresentados dentro de caixas de texto, para se diferenciarem de outras citações diretas. 
a natureza, que não é constituída do nada, torna-se humanizada por meio do trabalho consciente do ser humano. Com isso, o homem, como um ser da natureza, penetra nela por meio do conhecimento e a domina com seus instrumentos para reencontrá-la de modo mais profundo (LEFEBVRE, 1991).

Com a melhoria dos microscópios, devido ao desenvolvimento da óptica, da qualidade das lentes e dos meios de coloração das membranas, o modo de olhar a célula foi se modificando. Desta forma, diversas pesquisas entre o final do século XVII e início do século XIX proporcionaram a formulação da Teoria Celular. Constatou-se que a influência dos fatores externos estaria associada aos avanços tecnológicos da microscopia para atender às necessidades dos pesquisadores, colaborando para o desenvolvimento da Citologia. Os livros analisados dão ênfase a essa questão. Vejamos:

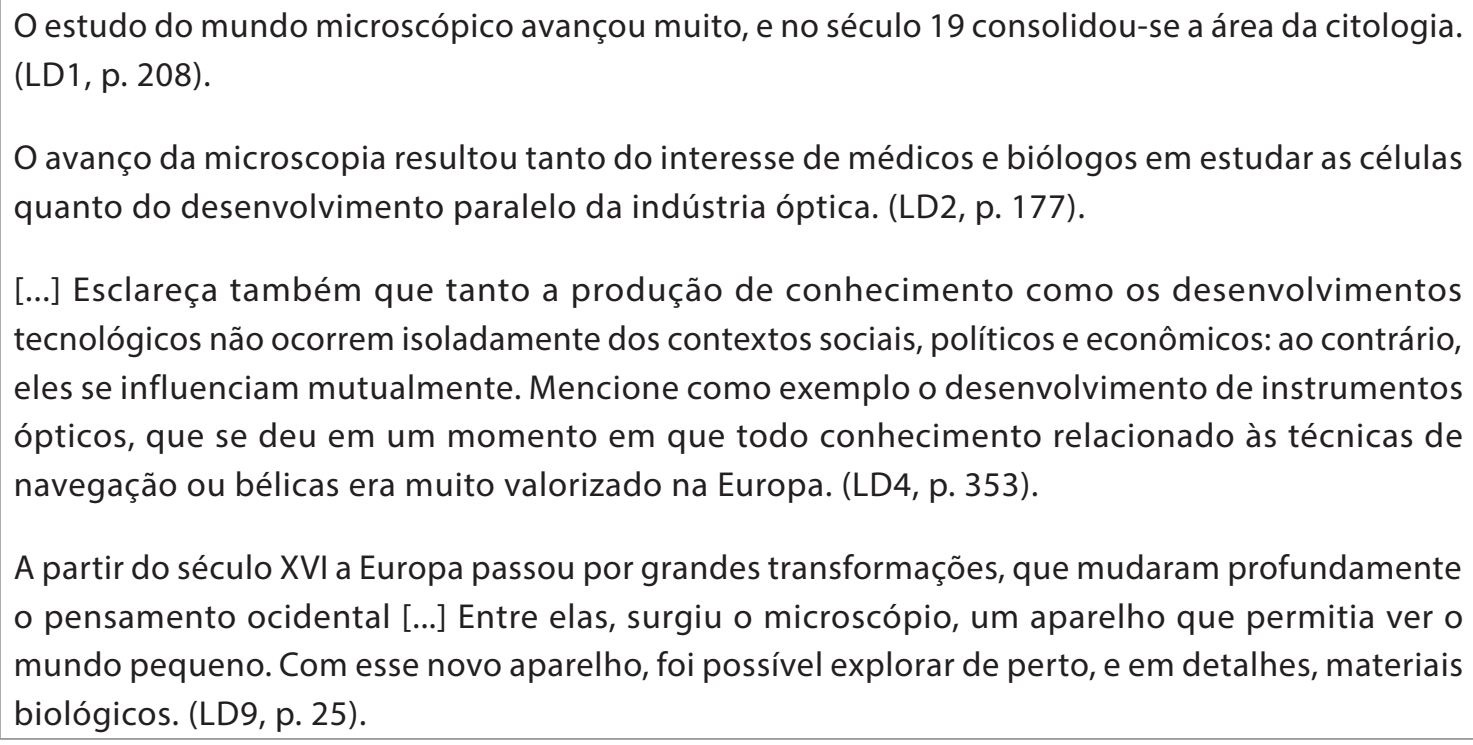
tecnológicos não ocorrem isoladamente dos contextos sociais, políticos e econômicos: ao contrário, eles se influenciam mutualmente. Mencione como exemplo o desenvolvimento de instrumentos ópticos, que se deu em um momento em que todo conhecimento relacionado às técnicas de navegação ou bélicas era muito valorizado na Europa. (LD4, p. 353).

A partir do século XVI a Europa passou por grandes transformações, que mudaram profundamente o pensamento ocidental [...] Entre elas, surgiu o microscópio, um aparelho que permitia ver o mundo pequeno. Com esse novo aparelho, foi possível explorar de perto, e em detalhes, materiais biológicos. (LD9, p. 25).

Os excertos acima apontam a tentativa dos autores desses livros didáticos de compreender a Ciência como uma atividade humana, como um conhecimento sistematizado de valores compartilhados em diferentes momentos históricos. Entretanto, nenhum dos livros analisados favoreceram a construção do pensamento biológico a partir da origem política das sociedades científicas, desvalorizando as influências socioculturais.

Observamos que esses livros apresentam o caráter do lema aprender a aprender presente no discurso oficial de documentos que sustentam a configuração do PNLD, como os parâmetros curriculares e o relatório Educação: um tesouro a descobrir (EDUCAÇÃO..., 2010), organizado pela UNESCO e por Jacques Delors, à Comissão Internacional sobre Educação para o Século XXI, como pode ser observado nos excertos a seguir: 
Um dos mais desafiadores e, ao mesmo tempo, imprescindíveis objetivos da educação é desenvolver nos estudantes a capacidade de buscar informações em diversas fontes e em diferentes contextos para que se tornem capazes de aprender sempre, inclusive para que possam aprender sozinhos. (LD8, p. 327 , grifo nosso).

Dessa maneira, qualquer educando tem condições de utilizar seus recursos internos para que sejam realizadas as atividades. E é nesse ponto que o educando pode tomar consciência de suas potencialidades para a execução das tarefas. [...] Quanto à afirmação de que é preciso estimular a postura ativa do aluno, [...], cabe ao aluno a maior responsabilidade por sua realização e ao professor, a posição de apresentar as ideias mais significativas possíveis. O educador deve orientar os educandos no processo de aprendizagem, mas a organização das ideias é tarefa do educando, pois é ele quem deverá ter a capacidade de torná-las significativas em sua estrutura cognitiva particular. (LD1, p. 351, grifo nosso).

Na pedagogia das competências e habilidades a escola passa a ter a tarefa de preparar os cidadãos para adaptar-se às alienadas e alienantes relações sociais que sustentam o capitalismo, mais uma vez acarretando o esvaziamento do trabalho educativo escolar, tornando-o um processo sem conteúdo e sem a apropriação do conhecimento do saber construído historicamente (DUARTE, 2004).

Desse modo, a relação de autonomia proposta ao estudante é perversa, pois não estão postos meios de lhe garantir autonomia de pensamento e sim a responsabilização pelo seu fracasso. Com isso, fortalece o ideal de que a construção do conhecimento deve ser guiada pelos interesses e necessidades dos estudantes, todavia não se leva em consideração as condições materiais concretas e contextos de cada sujeito e nem do mundo que se almeja construir.

\section{O Conceito de Célula nos Livros Didáticos: os estatutos estruturantes da Biologia como fundamento analítico}

Os aspectos pedagógicos da matriz de coleta de dados fundamentam-se, como já mencionado, nos pressupostos dos Estatutos Estruturantes da Biologia (NASCIMENTO JÚNIOR, 2010); logo partimos do pressuposto que os LD devem apresentar os conteúdos por meio de sua construção lógica e histórica ao longo da história da humanidade, pois contribuem como fonte de conhecimento ao envolvidos no processo de ensino e aprendizagem.

Ao investigarmos o modo como esse conhecimento está vinculado ao conceito de célula nos LD analisados, observamos que estes livros reafirmam a ideia de que a célula é a unidade constituinte dos seres vivos, sendo fundamental conhecê-la para entender o fenômeno da vida (Quadro 3). 
Quadro 3 - Síntese dos estatutos ontológico, epistemológico e histórico-social quanto ao conceito de célula nos LD analisados

\begin{tabular}{|c|c|c|c|c|}
\hline \multicolumn{2}{|r|}{ Elementos da análise } & \multirow[t]{2}{*}{ Síntese qualitativa dos dados } & \multicolumn{2}{|c|}{ Escala Likert } \\
\hline & & & Escala* & LD \\
\hline \multirow{4}{*}{$\begin{array}{l}\frac{3}{2} \\
\frac{0}{0} \\
\frac{0}{2} \\
\frac{0}{2}\end{array}$} & $\begin{array}{l}\text { Elucida o movimento histórico de } \\
\text { construção do conceito de vida? }\end{array}$ & $\begin{array}{l}\text { Fundamental para entender o funciona- } \\
\text { mento dos seres vivos }\end{array}$ & $+/-$ & Todos \\
\hline & \multirow[t]{2}{*}{$\begin{array}{l}\text { Esclarece a construção histórica do } \\
\text { conceito de organismo? }\end{array}$} & \multirow[t]{2}{*}{$\begin{array}{l}\text { Sistema em interação necessário para } \\
\text { manter a célula viva }\end{array}$} & + & $\begin{array}{l}1,2,3,4 \\
7,9\end{array}$ \\
\hline & & & $+/-$ & $5,6,8$ \\
\hline & $\begin{array}{l}\text { Elucida o movimento histórico de constru- } \\
\text { ção do conceito de vida? }\end{array}$ & $\begin{array}{l}\text { Rede de interações necessárias para a } \\
\text { manutenção da vida }\end{array}$ & $+/-$ & Todos \\
\hline \multirow{5}{*}{$\begin{array}{l}\frac{0}{9} \\
\frac{0}{0} \\
\frac{0}{0} \\
\frac{5}{2} \\
\frac{5}{2} \\
\frac{2}{2}\end{array}$} & \multirow{2}{*}{$\begin{array}{l}\text { Favorece o processo de construção da } \\
\text { teoria celular, sinalizando modelos con- } \\
\text { sonantes com vertentes epistemológicas } \\
\text { contemporâneas? }\end{array}$} & \multirow{2}{*}{$\begin{array}{l}\text { Conhecimento científico como um } \\
\text { conjunto de informações verdadeiras e } \\
\text { definitivas }\end{array}$} & + & $2,4,7,9$ \\
\hline & & & $+/-$ & $1,3,5,6,8$ \\
\hline & \multirow[t]{2}{*}{$\begin{array}{l}\text { Apresenta o método científico na teoria } \\
\text { celular? }\end{array}$} & \multirow[t]{2}{*}{$\begin{array}{l}\text { Clássico, apresentando etapas definidas } \\
\text { de construção da Teoria Celular }\end{array}$} & + & 2 e 9 \\
\hline & & & $+/-$ & $\begin{array}{l}1,3,4,5,6 \\
7,8\end{array}$ \\
\hline & Apresenta o conceito de célula? & $\begin{array}{l}\text { Definição simples e direta, com modelo } \\
\text { explicativo que não se relaciona com outras } \\
\text { ciências }\end{array}$ & $+/-$ & Todos \\
\hline \multirow{7}{*}{ 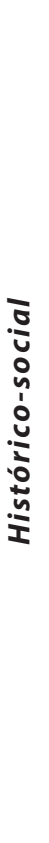 } & $\begin{array}{l}\text { Favorece o entendimento da construção } \\
\text { do pensamento biológico a partir da ideia } \\
\text { de não-linearidade da história da teoria } \\
\text { celular? }\end{array}$ & $\begin{array}{l}\text { Aponta o conhecimento científico } \\
\text { como resultado de um processo linear e } \\
\text { cumulativo }\end{array}$ & $+/-$ & Todos \\
\hline & $\begin{array}{l}\text { Relaciona o conhecimento biológico da } \\
\text { teoria celular, desenvolvido historicamente, } \\
\text { com as transformações tecnológicas? }\end{array}$ & $\begin{array}{l}\text { O estudo da célula se desenvolveu devido } \\
\text { às inovações microscópicas que surgiram } \\
\text { provenientes dos recursos tecnológicos }\end{array}$ & $+/-$ & Todos \\
\hline & \multirow{2}{*}{$\begin{array}{l}\text { Favorece o entendimento da construção } \\
\text { do pensamento biológico a partir das } \\
\text { interpretações dependentes do contexto } \\
\text { social em que foram produzidas? }\end{array}$} & \multirow{2}{*}{$\begin{array}{l}\text { Apresentam a produção científica como } \\
\text { uma atividade individual, deixando de dar } \\
\text { destaque aos diversos pesquisadores da } \\
\text { época }\end{array}$} & $+/-$ & $2,3,4,7,9$ \\
\hline & & & - & $1,5,6,8$ \\
\hline & \multirow{2}{*}{$\begin{array}{l}\text { Favorece a construção do pensamento } \\
\text { biológico a partir da origem política das } \\
\text { sociedades científicas? }\end{array}$} & \multirow[t]{2}{*}{$\begin{array}{l}\text { Não faz nenhuma relação com o contexto } \\
\text { político da época }\end{array}$} & $+/-$ & 4 \\
\hline & & & - & $\begin{array}{l}1,2,3,5,6 \\
7,8,9\end{array}$ \\
\hline & $\begin{array}{l}\text { Favorece a construção do pensamento } \\
\text { biológico a partir dos elementos } \\
\text { ideológicos do conhecimento biológico? }\end{array}$ & $\begin{array}{l}\text { Somente menciona a influência da } \\
\text { tecnologia para as novas descobertas da } \\
\text { Citologia, não expondo acontecimentos } \\
\text { filosóficos ou culturais que influenciaram } \\
\text { a Teoria Celular }\end{array}$ & $+/-$ & Todos \\
\hline
\end{tabular}

Fonte: elaborado pelos autores com base nos dados obtidos pela matriz de coleta de dados.

Pode-se observar que, ao explicitar a estrutura e o funcionamento das células, os livros analisados destacam a existência de uma imbricada rede de interações necessárias para a manutenção da vida. Ademais, apresentam uma visão indissociável da relação entre célula, natureza e organismo num sistema interligado e organizado que interage com o meio e com os outros seres vivos. Essa afirmação pode ser evidenciada pelos seguintes trechos: 


\begin{abstract}
[...] procurar compreender a estrutura e funcionamento das células, o que é fundamental para que possamos entender a intrincada rede de interações necessárias para a manutenção da vida. [...] com exceção dos vírus, os seres vivos são formados por células, e a compreensão de como eles surgiram e evoluíram passa pela compreensão de como a célula surgiu e evoluiu. (LD1, p. 207).

[...] compreendendo melhor o que é uma célula e como ela funciona, você poderá também compreender melhor "o que é a vida", o fenômeno que é o objeto de estudo da Biologia. (LD6, p. 163).

A célula é a estrutura mais simples capaz de desempenhar todas as atividades típicas de um organismo vivo: crescer, desenvolver-se, reproduzir-se e interagir com o meio que a cerca, extraindo dele nutrientes e energia e devolvendo-Ihe produtos de seu metabolismo. (LD7, p. 205).
\end{abstract}

Os conceitos de vida, organismos e natureza, de forma geral, se articulam em todos os livros e abordam, sucintamente e de maneira coerente, a construção do conhecimento científico - seu estatuto epistemológico. O modo de apresentar a historicidade nos LD analisados converge para um viés epistemológico que traz a visão rígida da Ciência como se idealiza o acontecimento de uma investigação, enquanto a visão cumulativa da história representa uma interpretação simplista da evolução dos conceitos científicos sem elencar, no processo de ensino, as contradições existentes entre as diferentes concepções.

Ao analisar como se dá o conceito de célula nos LD de Biologia por meio da produção do conhecimento biológico e das hipóteses, teorias, modelos e leis da Ciência (estatuto epistemológico), bem como em que contexto histórico-social esse conceito se construiu (estatuto histórico social), foi possível identificar que se desconsideram as regularidades e irregularidades dos fenômenos e processos biológicos a fim de construir generalizações. Falta ainda, nos livros analisados, a apresentação da Biologia de modo mais engendrado aos contextos histórico, social e cultural da humanidade (NASCIMENTO JÚNIOR, 2010).

Os resultados obtidos em nossa pesquisa são consoantes com os resultados obtidos nos estudos de Caurio (2011) no que se refere à visão de Ciência fragmentada, descontextualizada e fornecida como algo pronto, em detrimento da Ciência como um processo de construção humana. Megid Neto e Fracalanza (2003, p. 151) ratificam que tal visão está pautada na ideia de "[...] conhecimento científico como um produto acabado, elaborado por mentes privilegiadas, desprovidas de interesses político-econômicos e ideológicos".

Conseguimos identificar ainda que, mesmo arraigados nessa ideia de que somente alguns cientistas contribuíram efetivamente para a promulgação da Teoria Celular, os LD 2, 3, 4 e 9 buscaram demonstrar a Ciência como atividade coletiva, fruto de diferentes formas de produzir os conhecimentos biológicos. Vejamos alguns exemplos:

A elaboração da teoria foi resultado de várias pesquisas realizadas por diversos cientistas ao longo do tempo (LD3, p. 76).

As descobertas feitas por esses dois microscopistas estimularam outras pessoas a construir microscópios e fazer observações (LD4, p. 67). 
Identificamos, também, uma forte influência do modelo de Ciência empirista e positivista devido à generalização da teoria, que não faz referência à história da formação do conceito de célula, caracterizando uma visão aproblemática e a-histórica da Ciência - dogmática e fechada (GIL PÉREZ et al., 2001). O que acaba por transmitir a ideia de que a produção do conhecimento se dá exclusivamente pelo papel da observação e da experimentação, com conceitos já elaborados, sem destacar hipóteses, dificuldades e limitações que influenciaram a formulação do conhecimento.

Surgia, assim, a teoria celular de Schwann e Schleiden: 'Todos os seres vivos são formados por células'. (LD3, p. 76).

[...] os cientistas chegaram juntos à conclusão de que os seres vivos são formados por células que podem se diferenciar em relação ao formato e à função (LD5, p. 112).

[...] a célula é o 'denominador comum' da imensa variedade de formas de vida. (LD8, p. 40).

[...] essa teoria propõe três fundamentos básicos. São eles: todas as formas de vida são constituídas por uma ou mais células; toda célula se origina de uma célula preexistente; a célula é a menor forma de vida (LD7, p. 202).

Os LD trazem ainda referências às observações e às descrições dos experimentos com o auxílio do microscópio como uma sequência de etapas definidas a serem seguidas de maneira mecânica. Com essa visão rígida, composta por resultados obtidos, os LD não dão destaque aos processos que constituem o conhecimento científico. Concordando com Gil Pérez et al. (2001), essa concepção abandona o papel essencial das hipóteses como orientadoras da investigação, bem como das teorias que fundamentam o processo.

Um dos materiais observados por Hooke foi a cortiça, extraída da casca de certas árvores e utilizada
na fabricação de rolhas. Ele verificou que esse material tinha baixa densidade por apresentar
inúmeros poros microscópicos [...] Daí surgiu o termo célula, diminutivo de cela, hoje consagrado
para designar a unidade constituinte dos seres. (LD2, p. 176).
[...] o cientista inglês Robert Hooke observou pedaços de cortiça com o auxílio de um microscópio
formado por duas ou mais lentes associadas dentro de um tudo de metal. Era o chamado microscópio
composto, semelhante aos microscópios de hoje. Ele descreveu pequenas cavidades no interior
daqueles pedaços e deu-lhes o nome de células. (LD3, p. 75).

O LD 9 faz uma ressalva aos fundamentos básicos da Teoria Celular com estudos mais recentes no campo da Bioquímica e da Microbiologia, possibilitando uma dinamicidade da construção histórica do conceito de célula.

\footnotetext{
Em sua formulação moderna, a teoria celular [...] estabelece que: no interior das células ocorre o grande conjunto de reações químicas que mantêm os organismos vivos, como as reações de oxidação dos alimentos e a fabricação de substâncias, como as proteínas (LD 9, p. 26).

Von Sachs discordava da ideia de que um organismo fosse apenas a soma de suas células e propôs o que ficou conhecido como teoria orgânica. De acordo com esta teoria, o conjunto de células de um organismo adquire propriedades muito diferentes daquelas que as células isoladas possuem, o que chamamos hoje de propriedades emergentes. A formulação moderna da Teoria Celular admite parte das duas teorias originais, tanto a de von Sachs como a de Schleiden e Schwann (LD 9, p. 27).
} 
Silva (2014), em um estudo envolvendo os livros didáticos do PNLD 2012, constatou do mesmo modo, que há a predominância de visões deformadas das Ciências, o que contribuiu para a construção de uma imagem de Ciência descontextualizada e socialmente neutra. A autora sugere que os autores de livros didáticos devem ampliar sua formação com estudos histórico-filosóficos sobre a Ciência/Biologia ou estabelecer parcerias com historiadores especializados da Ciência, procurando evitar que a História e Filosofia da Ciência sejam apresentadas sob uma perspectiva deformada nos livros de Biologia.

Compreendemos que a construção do pensamento biológico deve acontecer por meio da ideia da não linearidade da História da Biologia, da relação entre o conhecimento biológico e as transformações tecnológicas, dos conhecimentos biológicos como interpretações dependentes do contexto social em que foram produzidos, da origem política das sociedades científicas e dos elementos ideológicos do conhecimento biológico (NASCIMENTO JÚNIOR, 2010).

Com relação ao estatuto conceitual da Biologia, o conceito de célula é apresentado como definição e unidade morfofisiológica dos seres vivos, e não como um conceito. Ressalta-se que há a discussão sobre a exceção dos vírus (Quadro 4).

Quadro 4 - Síntese do estatuto conceitual quanto ao conceito célula nos LD analisados

\begin{tabular}{|c|c|c|c|c|}
\hline \multicolumn{2}{|r|}{ Elementos da análise } & \multirow[t]{2}{*}{ Síntese qualitativa dos dados } & \multicolumn{2}{|c|}{ Escala Likert } \\
\hline & & & Escala* & LD \\
\hline \multirow{4}{*}{ 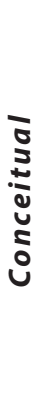 } & $\begin{array}{l}\text { Utiliza de modo claro e conciso os conceitos } \\
\text { e informações em exercícios, atividades, } \\
\text { ilustrações ou imagens? }\end{array}$ & $\begin{array}{l}\text { Definição básica de célula tanto no decorrer } \\
\text { do texto quanto nas atividades propostas }\end{array}$ & $+/-$ & Todos \\
\hline & $\begin{array}{l}\text { Apresenta conceitos, informações } \\
\text { e procedimentos de modo correto, } \\
\text { contextualizado e atualizado? }\end{array}$ & $\begin{array}{l}\text { Definição correta da célula, apontando } \\
\text { reflexões sobre a importância das células } \\
\text { com assuntos do cotidiano }\end{array}$ & $+/-$ & Todos \\
\hline & \multirow{2}{*}{$\begin{array}{l}\text { Aponta caminhos para problematização e } \\
\text { reflexão sobre o cotidiano? }\end{array}$} & \multirow{2}{*}{$\begin{array}{l}\text { Expõem perguntas que possibilitam ao } \\
\text { aluno refletir acerca da importância das } \\
\text { células ao estudo da Biologia }\end{array}$} & + & $2,4,5$ \\
\hline & & & $+/-$ & $\begin{array}{l}1,3,6,7, \\
8,9\end{array}$ \\
\hline
\end{tabular}

Fonte: elaborado pelos autores com base nos dados obtidos pela matriz de coleta de dados.

Entendemos que a definição é uma delimitação do conteúdo de um determinado conceito, ou seja, explanação do significado de uma palavra ou descrição de um objeto, sendo um elemento necessário para a construção dos conhecimentos científicos.

[...] as células são as unidades básicas dos organismos. (LD3, p. 74).

As células são as unidades fundamentais de todos os seres vivos. (LD8, p. 40).

[...] é ver a célula como uma estrutura dinâmica, um labirinto membranoso ocupado por um fluido gelatinoso, onde as reações acontecem de forma organizada, eficiente e econômica. A célula é a menor estrutura capaz de executar as atividades que caracterizam os seres vivos, razão pela qual o estudo da célula é fundamental para a compreensão da biologia. (LD8, p. 39).

O conceito, por sua vez, é uma estrutura mais complexa que uma definição, pois é a representação mental de um instrumento simbólico, de um objeto real em nossa mente, por meio das abstrações advindas de propriedades comuns a uma classe de objetos. Dessa maneira, "[...] um conceito não é uma formação isolada, 
fossilizada e imutável, mas sim parte ativa do processo intelectual, constantemente a serviço da comunicação, do entendimento e da solução de problemas" (VYGOTSKY, 2013, p. 67).

Os LD analisados apresentam definições e modelos explicativos que podem ser expandidos para a compreensão entre as diversas áreas do conhecimento, por meio da aplicação da lógica, apontando para uma melhor assimilação dos fenômenos biológicos. De maneira geral, articulam a construção do conhecimento sobre a Teoria Celular com o tema estruturador e de identidade dos seres vivos. De fato, quatros livros (LD2, LD4, LD7 e LD9) abordam a origem e evolução da vida nesse contexto.

\footnotetext{
A teoria celular é uma das mais importantes generalizações da Biologia. Ela propõe que os seres vivos, apesar das diferenças, têm em comum o fato de serem constituídos por células. Isso permite pensar que há um parentesco evolutivo entre todos os seres vivos. (LD2, p. 177).

No século XX, com o surgimento dos microscópios eletrônicos, descobriu-se que o interior da célula é ocupado por muitas e variadas estruturas altamente especializadas, responsáveis pelas funções capazes de manter a célula viva. As semelhanças observadas na estrutura básica das células dos diferentes organismos sugeriam um padrão comum em sua organização, o que reforçou as ideias de que os primeiros seres vivos eram de fato unicelulares e que os demais organismos evoluíram a partir deles. (LD4, p. 66).
}

Os livros didáticos analisados, também, apontam caminhos para a reflexão e problematização do conceito de célula no cotidiano, por meio de indagações sobre o papel das células e dos vírus e sobre o quanto o funcionamento das células é fundamental para a manutenção da vida. [...] os vírus não são constituídos de células, embora sejam feitos de dois tipos de moléculas
orgânicas características de todos os seres vivos - proteína e ácido nucleico. Além disso, os vírus
somente se reproduzem no interior das células vivas. E agora? Vírus são seres vivos? Ou não?
(LD2, p. 174).
Como é possível estudar estruturas tão pequenas como as células? Por que os vírus são considerados
um caso à parte quando estudamos seres vivos? (LD3, p. 74)..

Ademais, podemos afirmar, por meio da análise realizada nesta pesquisa, como atividade de síntese, que a célula é considerada a unidade básica de organização dos seres vivos e a menor parte deles, sendo composta essencialmente por uma fronteira (denominada de membrana plasmática), um sistema metabólico e o material genético. Essas partes fundamentais da célula atuam de maneira autônoma, dinâmica, e acopladas estruturalmente para o funcionamento do ser vivo como um todo. Além disso, sabemos que o avanço da tecnologia e a invenção do microscópio proporcionaram saltos nos estudos da célula, pois possibilitaram compreender que elas se originam de outras células preexistentes, e que os vírus são uma exceção nos modos de organização celular; que a dinâmica das células é fundamental para o entendimento de conceitos da Biologia Molecular e da Genética, bem como que pode contribuir para o diagnóstico de doenças; que o avanço na compreensão da célula transformou os estudos da vida e permitiu o entendimento da natureza.

Vemos como é necessário inserir os estudos da História e Filosofia da Ciência no ensino de Biologia, para que esse processo de aprendizado tenha "[...] uma abordagem 
contextualizadora, podendo trazer para o ensino os contextos ético, social, histórico, filosófico e tecnológico envolvidos na atividade científica" (NASCIMENTO JÚNIOR; SOUZA; CARNEIRO, 2011, p. 226). Tal ação nos possibilitaria pensar na discussão do conhecimento biológico como um produto social que sofre com modificações e contradições ao longo de sua história.

Portanto, ao adotar um LD, o professor deve ter um olhar crítico e atitude emancipadora sobre o processo de construção do pensamento biológico disposto nesse recurso didático, tendo em mente que o conhecimento científico tem caráter histórico e cultural e que a socialização do saber sistematizado possibilita aos estudantes apropriarem-se desse conhecimento e reestruturá-lo para efetivar seu desenvolvimento intelectual.

\section{Considerações Finais}

A matriz de análise proposta nesta pesquisa, fundamentada num rigor metodológico, epistemológico e histórico-social, nos permitiu perceber as contradições e fragilidades teóricas e estruturais presentes nos conteúdos dos LD, o que contribui para a pesquisa da área da Educação em Ciências, bem como para o trabalho docente.

Os resultados encontrados indicam que a forma como o conteúdo célula está disposto nos livros didáticos analisados não viabiliza a compreensão do pensamento biológico como parte integrante de um processo sócio-histórico. Indicam, também, que a construção do conceito de célula é permeada por uma visão ontológico-mecanicista da Biologia, justificada pela relação com a identidade dos seres vivos, e por uma visão epistemológica e sócio-histórica, na qual o método científico é reconhecido como empírico-indutivista, ou seja, uma Ciência linear e com uma produção científica como uma atividade individual, de visão aproblemática e a-histórica da Ciência, logo dogmática e fechada.

Destarte, entendemos que esses livros precisam adequar-se aos documentos curriculares vigentes no sistema educacional brasileiro. Todavia, o pensamento biológico, porém, não deve ser assimilado pela visão da aplicabilidade, sendo fundamental que o conhecimento científico, ao ser ensinado nas escolas, dê destaque ao seu processo de construção, "[...] não sendo compreendido como meramente instrumental, mas como um componente essencial para a leitura crítica da realidade multifacetada" (NASCIMENTO JÚNIOR, 2010, p. 399).

O pensamento por conceito é fundamental para o processo de apropriação do conhecimento biológico, visto que eles não são limitados às definições, mas sob todos os aspectos que o constituem (epistemológico, histórico-social e ontológico) (NASCIMENTO JÚNIOR, 2010). Para tanto, acreditamos que para os LD melhorarem sua qualidade devem apresentar a Ciência como um processo dinâmico do conhecimento humano, incorporando uma concepção epistemológica com base nos estudos históricofilosóficos dos conteúdos biológicos. Eles precisam conseguir integrar os conhecimentos por meio da contextualização, valorizando a função social da escola e promovendo a construção e reflexão crítica dos conceitos científicos.

É pertinente ressaltar que não queremos idealizar o LD ao problematizar essa dimensão pedagógica. Entendemos que a relação tempo-espaço precisa ser outra para todos os conteúdos da Biologia ser trabalhados pela abordagem histórico-filosófica. 
Essa sugestão vai ao encontro da id eia de se lutar por uma sociedade com desenvolvimento da atividade e da consciência humana, na busca por igualdade de direitos, rompendo com uma política educacional pobre, desigual, alienada e alienante.

Nessa perspectiva, esta pesquisa contribui para uma releitura do LD que, para além de uma visão sobre os aspectos técnicos e conteudistas, deve também subsidiar a construção de uma Educação mais crítica e emancipadora.

\section{Agradecimentos}

Agradecemos à Fundação de Amparo à Pesquisa do Estado de Goiás (FAPEG) pelo apoio financeiro, por meio da bolsa de estudo, em nível de mestrado, concedida à primeira autora desse artigo, oportunizando a realização dessa pesquisa.

\section{Referências}

AMABIS, J. M.; MARTHO, G. R. A descoberta das células. In: AMABIS, J. M.; MARTHO, G. R. Biologia em contexto. São Paulo: Moderna, 2013. p. 172-177.

BARBOSA, T. A. P. Historicidade e atualidade do estudo da célula nos livros didáticos de ciências do ensino fundamental. 2014. 137 f. Dissertação (Mestrado em Ensino de Ciências e Matemática) Faculdade de Educação, Universidade Estadual de Campinas, Campinas, 2014. Disponível em: http://repositorio.unicamp.br/jspui/handle/REPOSIP/253957. Acesso em: 11 fev. 2021.

BIZZO, N. A organização básica da vida. In: BIZZO, N. Novas bases da biologia. 2. ed. São Paulo: Ática, 2013. p. 24-27.

BRÖCKELMANN, R. H. A descoberta da célula. In: BRÖCKELMANN, R. H. Conexões com a biologia. São Paulo: Moderna, 2013. p. 108-112.

CAURIO, M. S. O livro didático de biologia e a temática citologia. 2011. 50 f. Dissertação (Mestrado em Educação em Ciências) - Universidade Federal do Rio Grande, Rio Grande, 2011.

CHOPPIN, A. História dos livros didáticos e das edições didáticas: sobre o estado da arte. Educação e Pesquisa, São Paulo, v. 30, n. 3, p. 549-566, 2004. DOI: https://doi.org/10.1590/S151797022004000300012.

CRESWELL, J. W. Projeto de pesquisa: métodos qualitativo, quantitativo e misto. Porto Alegre: Artmed, 2007.

DUARTE, N. Vigotski e o "aprender a aprender": crítica às apropriações neoliberais e pós-modernas da teoria vigotskiana. Campinas: Autores Associados, 2004.

EDUCAÇÃO: um tesouro a descobrir: relatório para a Unesco da Comissão Internacional sobre a Educação para o século XXI. Brasília: Unesco: Fundação Faber-Castell, 2010. Disponível em: https://unesdoc.unesco.org/ark:/48223/pf0000109590_por. Acesso em: 11 fev. 2021.

FAVARETTO, J. A. A célula: um sistema eficiente. In: FAVARETTO, J. A. Biologia: unidade e diversidade. São Paulo: Saraiva, 2013. p. 39-41.

FREITAS, L. M. Recursos didáticos em ensino de biologia: configurações epistemológicas da produção doutoral brasileira (1972-2014). 2016. 250 f. Tese (Doutorado em Educação em Ciências) - Universidade Federal de Mato Grosso, Cuiabá, 2016.

GIL PÉREZ, D.; MONTORO, I. F.; CARRASCOSA ALÍS, J.; CACHAPUZ, A.; PRAIA, J. Para uma imagem não deformada do trabalho científico. Ciência \& Educação, Bauru, v. 7, n. 2, p. 125-153, 2001. DOI: https://doi.org/10.1590/S1516-73132001000200001. 
LAJOLO, M. Livro didático: um (quase) manual de usuário. Em Aberto, Brasília, v. 19, n. 69, p. 3-9, jan. 1996. Disponível em: http://www.emaberto.inep.gov.br/ojs3/index.php/emaberto/article/ view/2368. Acesso em: 11 fev. 2021.

LEFEBVRE, H. Lógica formal lógica dialética. 5. ed. Rio de Janeiro: Civilização Brasileira, 1991.

LINHARES, S.; GEWANDSZNAJDER, F. Uma visão geral da célula. 2. ed. São Paulo: Ática, 2013.

LOPES, S.; ROSSO, S. Citologia e envoltórios celulares. In: LOPES, S.; ROSSO, S. Bio. 2. ed. São Paulo: Saraiva, 2013. p. 206-208.

MARTINS, I. Analisando livros didáticos na perspectiva dos estudos do discurso: compartilhando reflexões e sugerindo uma agenda para a pesquisa. In: MARTINS, I.; GOUVÊA, G. V. R.; VILANOVA, R. (ed.). O livro didático de ciências: contextos de exigência, critérios de seleção, práticas de leitura e uso em sala de aula. Rio de Janeiro: FAPERJ, 2012. p. 11-30.

MEGID NETO, J. N.; FRACALANZA, H. O livro didático de ciências: problemas e soluções. Ciência \& Educação, Bauru, v. 9, n. 2, p. 147-157, 2003. DOI: https://doi.org/10.1590/S151673132003000200001.

MENDONÇA, V. L. Introdução à citologia e membranas celulares. In: MENDONÇA, V. L. Biologia. 2. ed. São Paulo: AJS, 2013. p. 162-166.

NASCIMENTO JÚNIOR, A. F. Construção de estatutos de ciência para a biologia numa perspectiva histórico-filosófica: uma abordagem estruturante para seu ensino. 2010. $439 \mathrm{f}$. Tese (Doutorado em Educação para a Ciência) - Universidade Estadual Paulista, Bauru, 2010.

NASCIMENTO JÚNIOR, A. F.; SOUZA, D. C.; CARNEIRO, M. C. O conhecimento biológico nos documentos curriculares nacionais do ensino médio: uma análise histórico-filosófica a partir dos estatutos da biologia. Investigações em Ensino de Ciências, Porto Alegre, v. 16, n. 2, p. 223-243, 2011. Disponível em: https://www.if.ufrgs.br/cref/ojs/index.php/ienci/article/view/228. Acesso em: 11 fev. 2021.

OSORIO, T. C. et al. Introdução à citologia. In: OSORIO, T. C. Ser protagonista: biologia. São Paulo: SM, 2013. v. 1, p. 64-68.

PINHEIRO, R. M. S. O conceito de célula em livros didáticos de biologia: análise sob uma perspectiva histórico-crítica. 2018. 165 f. Dissertação (Mestrado em Educação em Ciências e Matemática) Universidade Federal de Goiás, Goiânia, 2018. Disponível em: http://repositorio.bc.ufg.br/tede/ handle/tede/8346. Acesso em: 11 fev. 2021.

RODRÍGUEZ PALMERO, M. L. R.; MOREIRA, M. A. Modelos mentales de la estructura y del funcionamiento de la célula: dos estudios de casos. Investigações em Ensino de Ciências, Porto Alegre, v. 4, n. 2, p. 121-160, 1999. Disponível em: https://www.if.ufrgs.br/cref/ojs/index.php/ ienci/article/view/606. Acesso em: 11 fev. 2021.

SILVA, E. C. C. A teoria celular em livros didáticos de biologia: uma análise a partir da abordagem histórico-filosófica da ciência. 2014. 292 f. Dissertação (Mestrado em Educação em Ciências e em Matemática) - Universidade Federal do Paraná, Curitiba, 2014. Disponível em: http://hdl.handle. net/1884/37267. Acesso em: 23 fev. 2021.

SILVA JÚNIOR, C.; SASSON, S.; CALDINI JÚNIOR, N. A célula, unidade fundamental dos seres vivos. In: SILVA JÚNIOR, C.; SASSON, S.; CALDINI JÚNIOR, N. Biologia. 11. ed. São Paulo: Saraiva, 2013. p. 201-205.

VASCONCELOS, S. D.; SOUTO, E. O livro didático de ciências no ensino fundamental: proposta de critérios para análise do conteúdo zoológico. Ciência \& Educação, Bauru, v. 9, n. 1, p. 93-104, 2003. DOI: http://dx.doi.org/10.1590/S1516-73132003000100008.

VYGOTSKY, L. S. Pensamento e linguagem. 2. ed. São Paulo: Martins Fontes, 2013. 